\title{
Erratum to: Institutionalizing Ethical Innovation in Organizations: An Integrated Causal Model of Moral Innovation Decision Processes
}

\author{
E. Günter Schumacher • David M. Wasieleski
}

Published online: 21 July 2012

(C) Springer Science+Business Media B.V. 2012

Erratum to: J Bus Ethics

DOI 10.1007/s10551-012-1277-7

The authors of the above mentioned article discovered an inversion of letters in Fig. 1 after its publication in OnlineFirst. During submission of the manuscript and in the proofreading stage they overlooked an inversion in 'Stage VI'. The correct caption should read 'Stage IV' as shown in the updated Fig. 1.

The online version of the original article can be found under doi:10.1007/s10551-012-1277-7.

E. G. Schumacher - D. M. Wasieleski

CEREFIGE-ICN Business School, Nancy-Metz,

13 Rue Michel Ney, 54000 Nancy, France

e-mail: gunter.schumacher@icn-groupe.fr

D. M. Wasieleski $(\bowtie)$

Duquesne University, 600 Forbes Avenue, 918 Rockwell Hall,

Pittsburgh, PA 15282, USA

e-mail: Wasieleski@duq.edu 


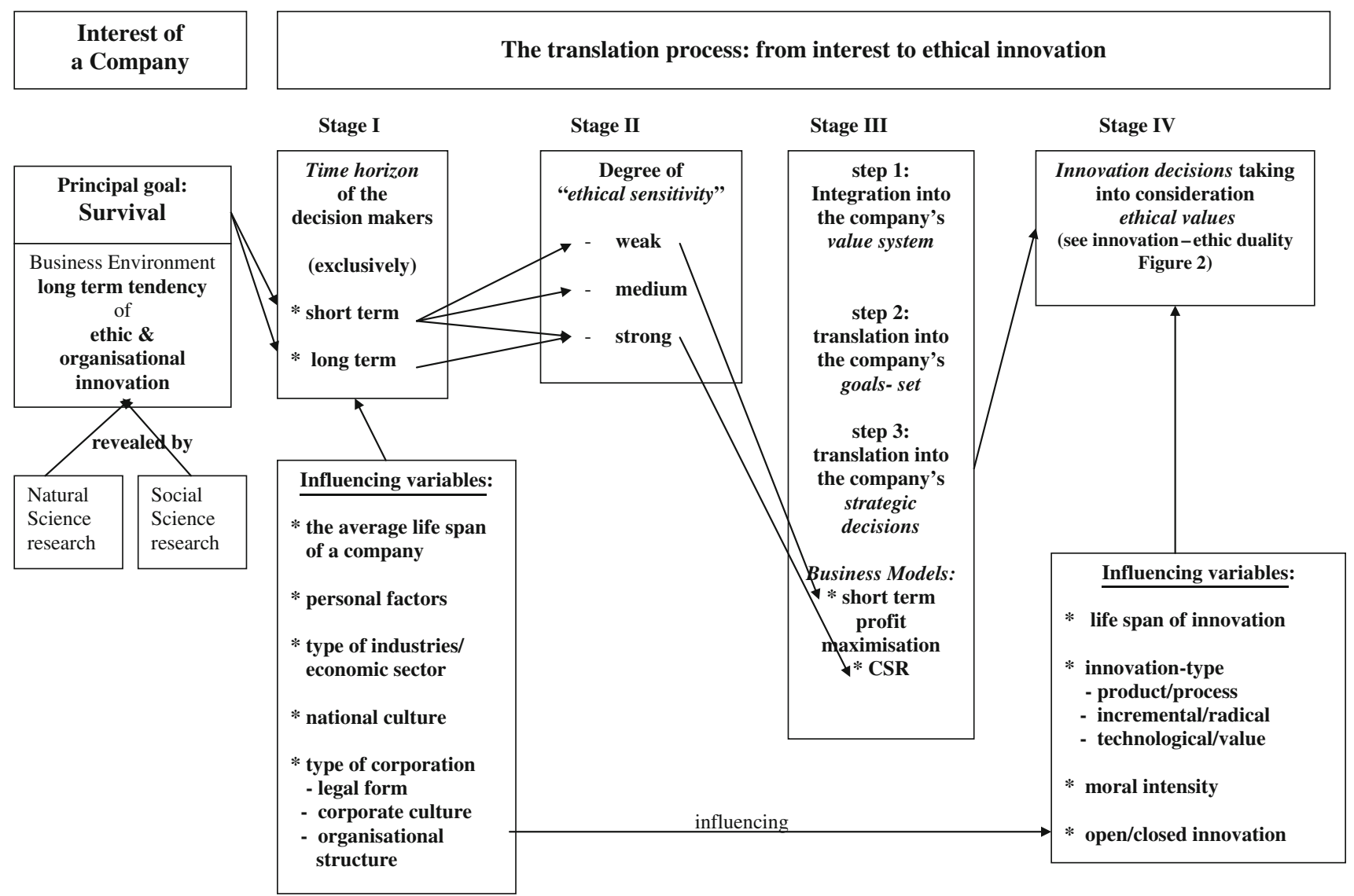

Fig. 1 The causal link between survival objective and ethical innovation 